\title{
EL PENSAMIENTO PEDAGÓGICO DE MARÍA Y RAMIRO DE MAEZTU Y EL PRIMER NEOKANTISMO ESPAÑOL
}

\author{
FERNANDO HERMIDA DE BLAS \\ Universidad Autónoma de Madrid
}

\begin{abstract}
RESUMEN: En este texto se estudia en primer lugar la influencia de la filosofía neokantiana de José del Perojo y Manuel de la Revilla, representantes del primer movimiento neokantiano español («Primera Escuela de Madrid»), en el pensamiento pedagógico de María de Maeztu y su hermano Ramiro. En segundo lugar, se presenta a los hermanos Maeztu como los eslabones intermedios entre ese primer neokantismo y el segundo movimiento neokantiano español, representado por José Ortega y Gasset y sus discípulos («Segunda Escuela de Madrid»).
\end{abstract}

PALABRAS CLAVE: pedagogía, neokantismo, «Escuela de Madrid», José del Perojo, Manuel de la Revilla, María de Maeztu, Ramiro de Maeztu, José Ortega y Gasset.

\section{María and Ramiro de Maeztu's pedagogy and the first spanish neokantism}

ABSTRACT: Firstly, we study the influence of José del Perojo's and Manuel de la Revilla's Neokantian Philosophy, main figures of the First Spanish Neokantism («Primera Escuela de Madrid»), in the Pedagogy of Maria de Maeztu and her brother Ramiro. Secondly, we show the Maeztus as a link of a chain between the First and the Second Spanish Neokantism, whose main figures were José Ortega y Gasset and his disciples («Segunda Escuela de Madrid»).

KEY WORDS: pedagogy, Neokantism, «Escuela de Madrid», José del Perojo, Manuel de la Revilla, María de Maeztu, Ramiro de Maeztu, José Ortega y Gasset.

\section{ANTECEDENTES Y ESTADO aCtUAL DE UNA INVESTIGACión EN CURSO}

Mi intención no es reconstruir en este texto la biografía intelectual de Ramiro de Maeztu, porque ya existen varios trabajos al respecto, ni tampoco la de María de Maeztu, a pesar de ser todavía escasos los estudios sobre su vida y su obra. En este último caso, sólo se pueden citar la breve aproximación biográfica de María Cristina Fructuoso Ruiz de Erenchun María de Maeztu Whitney, una vitoriana ilustre, publicada en 1998 por la Real Sociedad Bascongada de los Amigos del País, y, como monografía fundamental, la Tesis doctoral de Isabel Pérez-Villanueva Tovar María de Maeztu: una mujer en el reformismo educativo español, publicada en 2003 por la Universidad Nacional de Educación a Distancia. También existe algún trabajo sobre aspectos concretos de su pensamiento, pero poco más.

Por el contrario, quiero centrarme en un aspecto concreto que hasta ahora no ha merecido suficiente atención de los estudiosos: la proyección del neokantismo alemán y del neokantismo español sobre el pensamiento pedagógico de los hermanos Maeztu, Ramiro y María, cuya actividad intelectual en este campo tiene una clara interrelación.

Este tema despertó nuestro interés durante las investigaciones que el grupo de la Universidad Autónoma de Madrid $^{1}$ ha venido realizando de forma continuada desde

1 El grupo de investigación registrado por la Dirección general de Investigación de la Comunidad de Madrid bajo la denominación «Historia del Pensamiento Español/UAM» ha estado coordinado por el profesor José Luis Mora García y ha estado compuesto por los profesores Diego Núñez Ruiz (actualmente jubilado), Pedro Ribas Ribas (actualmente jubilado) y Fernando Hermida de Blas. En 2005 se incorporó 
hace varios años sobre la «recepción del neokantismo alemán en España» desde las figuras de José del Perojo y Manuel de la Revilla hasta José Ortega y Gasset, pasando por los Maeztu, que fueron a la vez discípulos y maestros de Ortega. Anteriormente varios miembros del grupo habían realizado aproximaciones más o menos directas al tema: la primera fase de estos estudios se inició con el libro de Diego Núñez La mentalidad positiva en España: desarrollo y crisis (Madrid, Túcar, 1975), continuó con los cursos de Doctorado impartidos por los miembros del grupo en la Universidad Autónoma de Madrid a finales de los años 80 y principios de los 90 del siglo xx y culminó con la Tesis doctoral de María Dolores Díaz Regadera titulada José del Perojo y Figueras (1850-1908). Neokantismo y reformismo, publicada en 1996 por Ediciones de la Universidad Autónoma de Madrid, en la que se ofrecía la primera biografía intelectual de José del Perojo, introductor del neokantismo en España.

Una segunda fase comenzó en 2001, con el proyecto de investigación que desarrollamos para completar dicha biografía intelectual ${ }^{2}$. Esta investigación tuvo como resultado más tangible el libro Artículos filosóficos y políticos de José del Perojo (1875-1908), también publicado por Ediciones de la Universidad Autónoma de Madrid en 2003.

Todas estas investigaciones contribuyeron al conocimiento de un interesante personaje polifacético (filósofo, político, periodista y editor) casi completamente desconocido de quien conviene adelantar aquí algunos datos biográficos relevantes para el tema abordado.

José del Perojo y Figueras, nacido en Santiago de Cuba el 19 de enero de 1850, inició sus estudios en Santander, provincia de donde provenía su padre, rico indiano que falleció tempranamente. Con la fortuna heredada, José del Perojo diseñó su propio programa de formación universitaria, lo que le llevó a viajar a Inglaterra, Francia y Alemania para obtener una educación que no creía poder encontrar en España. Especialmente significativo fue su paso por la Universidad de Heidelberg, donde conoció a Kuno Fischer (1824-1907), figura destacada de la Primera Escuela Neokantiana Alemana o «Escuela de Heidelberg». La primera obra de Perojo fue el ensayo «Arthur Schopenhauer», publicado en 1875 en los Philosophische Monatshefte de Leipzig, uno de los principales órganos culturales de los neokantianos.

Perojo creyó haber encontrado en el neokantismo la filosofía que podría servir de fundamento intelectual a la modernización de España en los campos científico, económico, social y cultural, así como el medio de superar la crisis en la que se veía inmerso el liberalismo español desde el fracaso del krausismo durante el Sexenio revolucionario. A su regreso a la Península, se embarcó en el proyecto de renovar el panorama intelectual, difundir el pensamiento científico moderno y «europeizar» España: primero, con la publicación en 1875 de sus Ensayos sobre el movimiento intelectual en Alemania, condenados en 1877 por el Vaticano debido a la defensa que en ellos se hace de las doctrinas naturalistas de Charles Darwin y Ernst Hæckel; segundo, con la fundación, en diciembre de 1875, de la Revista Contemporánea, principal publicación científica y cultural de

el profesor Antonio Jiménez García (Universidad Complutense de Madrid, fallecido en 2008). A partir del año 2009 ha sido incluido en el Registro de Grupos de Investigación de la Universidad Autónoma de Madrid bajo la denominación F-074 «Historia del Pensamiento Español e Iberoamericano» y, siempre bajo la coordinación de José Luis Mora, ha estado compuesto desde entonces por los profesores Ángel Casado Marcos de León (emérito), Juana Sánchez-Gey Venegas, Fernando Hermida de Blas, Gemma Gordo Piñar y Pedro Ribas Ribas (recordamos, actualmente jubilado).

2 «La primera Escuela de Madrid» (REF ${ }^{a}$ 06/0173/2000), financiado por la Dirección General de Investigación de la Comunidad de Madrid. 
España y plataforma publicitaria de las corrientes filosóficas más avanzadas, de la que fueron redactores jefes Rafael Montoro (1852-1933) y Manuel de la Revilla (1846-1881).

Perojo y Revilla participaron en la «tercera polémica de la ciencia española», iniciada en 1876, en la que sostuvieron que en España no había habido más filosofía que la escolástica tomista debido a la perniciosa influencia de la intolerancia religiosa y el despotismo político, que acabaron con la libertad de pensamiento, unidos a un fallo esencial en el carácter nacional español que dificulta el desarrollo de la racionalidad y la ciencia modernas.

Perojo fundó en 1877 la revista La Naturaleza y la Editorial Perojo, de marcada orientación filosófica y científica, dedicada a ofrecer al público traducciones directas de obras de autores extranjeros para vivificar la cultura nacional al contacto con la europea. Entre ellas es preciso mencionar la primera versión al español del Origen de las especies de Darwin y de las Obras filosóficas de Descartes, esta última debida a Revilla.

En 1879 Perojo se arruinó, cerró la editorial, vendió sus revistas y se trasladó a París, donde rehizo su fortuna. Después regresó a España y retomó sus empresas culturales. Así, en 1883 tradujo la Crítica de la razón pura de Immanuel Kant y en 1885, en colaboración con Enrique Camps, La descendencia del hombre y la selección en relación al sexo de Darwin. A partir de entonces desplazó su interés de los problemas filosóficos a los económicos, sociales y políticos, en especial a los que afectaban a la relación de las colonias españolas con la Metrópoli, aunque la impronta neokantiana nunca le abandonó. Promovió el trato igualitario de los territorios ultramarinos para llegar a su total identificación con los peninsulares. Llevó a cabo esta defensa de las colonias desde su destacada labor como periodista y empresario cultural y desde los cargos políticos que desempeñó durante el resto de su vida.

Perojo inició en 1886 su actividad política como diputado fusionista por Caldas (Pontevedra). Ese mismo año se arruinó por segunda vez debido al elevado coste económico que le supuso la fundación y dirección del periódico La Opinión. En 1889 fue nombrado Gobernador Civil de Manila, puesto al que renunció en 1890. En 1891 y 1893 fue candidato por Santander, pero el fraude electoral institucionalizado le impidió ocupar el escaño que le pertenecía. Desilusionado, se alejó del fusionismo para vincularse al Partido Autonomista Cubano, y obtuvo en 1894 un escaño por La Habana. Ese mismo año fundó y dirigió el semanario El Nuevo Mundo (Nuevo Mundo desde 1895), su publicación más exitosa, que continuaría existiendo incluso tras su muerte. En 1898 fue reeligido diputado por La Habana. Defensor de la terminación de la Guerra de Cuba, manifestó su desconfianza hacia el sistema de la Restauración borbónica y abandonó la política. Así, en 1899 centró su actividad en empresas culturales, fundando la Editorial Nuevo Mundo y, en 1900, Por esos Mundos y El Teatro. Sin embargo, en 1905 volvió a la política activa, siendo elegido diputado por Las Palmas de Gran Canaria en el seno del Partido Conservador de Antonio Maura, por quien profesó gran admiración. Fundador de la Asociación de la Prensa Española, en 1906 centró su actividad en la defensa de la libertad de prensa. Pero en 1907, tras ser reelegido diputado por Las Palmas, inició una campaña a favor de la descentralización administrativa de las Islas Canarias. Ese mismo año empezó a dedicar su atención periodística y política a las cuestiones educativas, publicando una de sus obras fundamentales, Ensayos sobre educación. En 1908 realizó frecuentes viajes a Inglaterra en compañía de Ramiro de Maeztu para comparar la situación de la educación en España respecto de Europa y reunió en el volumen La educación española algunos de los discursos parlamentarios que dedicó a esta cuestión. 
José del Perojo murió el 17 de octubre de 1908 en su escaño del Parlamento, mientras escuchaba una réplica a una enmienda suya al proyecto de reforma de la Administración local encaminada a lograr la división biprovincial de las Islas Canarias.

Pues bien, conviene adelantar ya que durante nuestro estudio de la vida y la obra de Perojo encontramos interesantes conexiones directas con los hermanos Maeztu que van más allá de ese plano puramente personal o familiar al que en 1994 se había referido Román Gubern en su biografía de Benito Perojo, famoso cineasta e hijo natural de José $^{3}$. Después trataré con algún detalle estas influencias de Perojo sobre los Maeztu.

En 2003 continuamos nuestra reconstrucción de la «recepción del neokantismo alemán en España» con un estudio sobre quien tradicionalmente ha sido considerado la otra figura más relevante del primer movimiento neokantiano español: Manuel de la Revilla ${ }^{4}$.

Como en el caso de Perojo, también es necesario adelantar aquí algunos datos biográficos que resultan relevantes.

Manuel de la Revilla Moreno, crítico, filósofo, poeta y periodista nacido en Madrid el 26 de octubre de 1846, inició sus estudios bajo la orientación de su padre, José de la Revilla Gironza, funcionario de la administración pública y promotor de la introducción en España de la filosofía krausista, quien lo formó en los principios del enciclopedismo francés.

Manuel de la Revilla se dedicó muy tempranamente, desde 1863, al ejercicio del periodismo. Sus primeras colaboraciones fueron en la prensa vinculada al republicanismo jacobino, federalista y progresista, corriente ideológica a la que se adscribió en un principio.

En 1866 obtuvo el grado de Licenciado en Derecho y en 1868 el de Licenciado en Filosofía y Letras, ambos por la Universidad Central. Tras ocupar varios puestos docentes en el Instituto del Noviciado, en el Colegio Internacional y en la Universidad Central, en 1872 defendió en la Facultad de Filosofía y Letras su Tesis doctoral referida a la Estética. Amplió su labor periodística a publicaciones próximas al republicanismo unitario, donde promovió el entendimiento entre los diferentes sectores republicanos y criticó el revolucionarismo extremista del liberalismo. El fracaso de sus propuestas le hizo virar hacia el republicanismo reformista, posibilista y conservador, al tiempo que se apartó de la política activa.

En los inicios de su formación, se vinculó a la filosofía idealista, principalmente al krausismo, aunque también hay en su pensamiento una veta netamente hegeliana. Sin embargo, pronto comenzó a abrirse a otras corrientes filosóficas y científicas más modernas, entre ellas las doctrinas naturalistas de Darwin, que defendió desde la tribuna del Ateneo de Madrid, donde ocupó diversos cargos de responsabilidad. En 1876 obtuvo la cátedra de Principios Generales de Literatura y Literatura Española de la Universidad Central, tras un largo proceso de cuatro años en el que se le intentó apartar de la oposición por considerar que sus alegatos en pro del darwinismo eran contrarios a las enseñanzas de la Iglesia católica.

Revilla fue un destacado poeta que recopiló parte de sus composiciones en el libro Dudas y tristezas, de 1875. El prólogo que Ramón de Campoamor puso a este volumen desató la «polémica sobre el panantheísmo», en la que intervinieron los defensores de

3 Gubern, R., Benito Perojo. Pionerismo y supervivencia. Madrid, Filmoteca Española, Instituto de la Cinematografía y de las Artes Audiovisuales, 1994.

4 «La primera Escuela de Madrid (II): Manuel de la Revilla (1846-1881)» (REFa 06/0134/2002), también financiado por la Dirección General de Investigación de la Comunidad de Madrid. 
la escuela krausista, sus detractores y quienes, como Revilla, se mantuvieron en una postura intermedia.

Fueron muchos sus trabajos como crítico en los campos de la literatura, la escena, la filosofía y la ciencia. Cabe destacar su labor en el diario El Globo a partir de 1875, donde se encargó de las secciones «Revista Teatral» y «Revista Bibliográfica». Su consagración se produjo en la Revista Contemporánea, fundada por José del Perojo en diciembre de 1875, de la que Revilla fue su más destacado redactor jefe. En concreto, se encargó de la sección fija «Revista crítica», donde desarrolló una crítica literaria más rigurosa y de carácter positivo, en lugar de la tradicional de carácter romántico, inaugurando así un nuevo estilo crítico en el panorama intelectual español. Pero no se limitó a tratar cuestiones meramente literarias, sino que empleó géneros «mestizos» para abordar todo tipo de problemáticas culturales, científicas, ideológicas y sociales, lo que hace muy difícil sistematizar sus contribuciones periodísticas y ofrecer un análisis cronológicotemático pormenorizado de las mismas, ya que prácticamente cada uno de sus artículos es un mundo propio dotado de enorme complejidad y con múltiples lecturas transversales y multidireccionales.

Como ya hemos señalado, Perojo y Revilla participaron en la «tercera polémica de la ciencia española», iniciada en 1876, en la que sostuvieron que en España no había habido más filosofía que la escolástica tomista debido a la perniciosa influencia de la intolerancia religiosa y el despotismo político, que acabaron con la libertad de pensamiento, unidos a un fallo esencial en el carácter nacional español que dificulta el desarrollo de la racionalidad y la ciencia modernas.

Entre sus últimos trabajos, Revilla publicó en 1878, en la Editorial Perojo, la primera traducción al español de las Obras filosóficas de Descartes.

En los estudios monográficos sobre Revilla se ha ofrecido una interpretación sobre la evolución de su pensamiento según la cual primero fue krausista, para, en 1875, convertirse en neokantiano por la influencia de Perojo. Otros comentaristas añaden que utilizó el neokantismo como paso intermedio hacia el positivismo que profesó al final de su vida. Él mismo afirmó que en un principio militó en el krausismo, pero luego lo abandonó para inscribirse en la corriente positivista. Más recientemente se ha sostenido que siempre practicó el eclecticismo: en un primer momento, entre el idealismo krausista y el hegeliano, para, alrededor de 1874, encaminar su filosofía hacia la recuperación del Kant de la Crítica de la razón pura y abrirse a nuevas corrientes como el neokantismo y el positivismo, sin renunciar nunca a ciertos componentes propios del idealismo.

En mayo de 1880 se agravaron los recurrentes trastornos mentales que sufría. Al cabo de un año pareció superar su enfermedad y retomó su labor intelectual. Se trasladó a San Lorenzo del Escorial para reponerse, pero falleció el 13 de septiembre de 1881, víctima de un ataque cerebral.

\section{Influencia del pensamiento de Manuel de la Revilla en el de Ramiro de Maeztu}

Como se ve, al reconstruir la biografía intelectual de Revilla descubrimos de entrada que éste, al contrario que Perojo, no puede ser considerado sin más un neokantiano: primero, porque su pensamiento juvenil fue producto de un sincretismo idealista y racionalista, principalmente krausista, pero también con resonancias hegelianas e incluso con ribetes cartesianos; segundo, porque aun después de asumir planteamientos neokantianos y positivistas nunca abandonó por completo otros propios del idealismo. Es decir, que Revilla puede ser calificado de «racionalista ecléctico». 
Sin embargo, neokantiano en sentido estricto o no, Revilla influyó indirectamente en el pensamiento de los hermanos Maeztu, en este caso, de Ramiro. Por supuesto, Ramiro no conoció a Revilla, fallecido en 1881. Pero, por ejemplo, su interpretación filosófico-literaria de El Quijote no puede entenderse sin la que Revilla había llevado a cabo años antes ${ }^{5}$.

Es bien conocida la importancia de este tema en el periodo comprendido entre 1890 y, al menos, la fecha de publicación del libro de Ramiro Don Quijote, Don Juan y la Celestina: Ensayos en simpatía (1926), que tuvo una larga gestación. Esta lectura de Ramiro se sitúa en un punto central de la controversia entre las interpretaciones literarias o historicistas y las filosóficas o simbólicas del libro cervantino. Las consecuencias de esta polémica superaban con mucho el ámbito de la teoría literaria hasta alcanzar un diagnóstico de la historia de España, o sea, de las teorías acerca de la naturaleza de la decadencia española. El propio Revilla había dedicado íntegramente al Quijote una decena de artículos, además de numerosas referencias en otros textos, donde criticaba algunos excesos cometidos en las lecturas simbólicas del texto desde la época romántica, pero sin llegar a aceptar tampoco las posturas puramente literarias de las que Valera era su mayor valedor. Sobre el personaje de Don Quijote, Ramiro habla en diálogo con varios de sus intérpretes incluido el propio Revilla, de quien, tras afirmar que era un espíritu amante de la verdad, transcribe un largo párrafo en el que sostiene su tesis equidistante de la posición historicista y de la puramente filosófica. Ramiro critica su posición, que considera contradictoria, aunque él mismo termina por sostener que el siglo xvı español pasará a la historia como modelo de lo que los hombres pueden y no pueden conseguir. Es decir, que si bien quiso superar la que consideraba contradicción en Revilla, ésta terminó por ser su propia tesis sobre El Quijote y, a la altura de 1926, sobre España. En definitiva, se trataba de debatir acerca del significado del personaje o del libro en la historia y en la cultura españolas y de ahí deducir una idea de España a partir de un debate aparentemente teórico acerca de las relaciones entre filosofía y literatura, que fue tema central en la reflexión intelectual durante más de tres cuartos de siglo, desde el primer krausismo hasta la generación de 1931. No en balde, Ortega dedicó a Ramiro la primera edición de Meditaciones del Quijote, con lo que venía a reconocer el papel del escritor/ periodista/filósofo en este debate que aunaba una cuestión epistemológica junto a la polémica por el problema, el ser (u otras denominaciones similares) de España.

Vistos estos antecedentes, el tercer paso lógico era acudir a Ramiro y María de Maeztu, para lo que desarrollamos un tercer proyecto de investigación en $2005^{6}$.

Sobre Ramiro, una de las figuras del pensamiento español que más atención ha logrado atraer durante bastantes años, hay numerosos estudios, ediciones de sus obras y recopilaciones de artículos. Aunque hemos comprobado lo mucho que queda por hacer, pues, por ejemplo, en las actuales recopilaciones no siempre se distingue entre artículos de Ramiro, resúmenes de sus conferencias, reseñas sobre éstas y sobre sus libros, artículos duplicados, refundiciones y variantes, lo que nos lleva a la necesidad de replantear sustancialmente el número de artículos que, hasta ahora, estaba justificado atribuir a este autor. El grupo de investigación ha trabajado sobre casi setenta publicaciones

5 Cfr. El estudio y reconstrucción de la interpretación filosófico-literaria de El Quijote realizada por Revilla ha sido una de mis contribuciones fundamentales al Proyecto de Excelencia Multidisciplinar «El Quijote en la cultura europea. Mito y representación» (REF CEMU-2012-017-01), financiado por la Universidad Autónoma de Madrid, en el que, desde 2012 hasta 2014, participan más de diez universidades europeas y norteamericanas».

6 "La "Escuela de Madrid": El eslabón intermedio: Ramiro y María de Maeztu» (REF ${ }^{\mathrm{a}}$ 06/ HSE/0019/2004), financiado por la Dirección General de Universidades e Investigación de la Comunidad de Madrid. 
periódicas y alrededor de cinco mil artículos, lo que supone más o menos trescientos no incluidos en recopilaciones anteriores, ni siquiera en las más extensas, y cerca de cuarenta más de los que sólo hemos encontrado referencias en diversos textos, porque no hemos podido localizar el periódico y/o la fecha concreta en que Ramiro los publicó, o ni siquiera hemos encontrado razones de peso para atribuirle su autoría sin lugar a duda. Estos cinco mil artículos constituyen una base de partida absolutamente fiable sobre la que se debe seguir trabajando, dado que Ramiro publicó en periódicos y revistas de numerosos países europeos y americanos.

Recapitulando, el nexo de los Maeztu con los primeros neokantianos españoles se ha comprobado más importante y decisivo de lo que se pensaba hasta ahora.

\section{Relación de José del Perojo con María y Ramiro de Maeztu}

Ya adelanté que el caso de José del Perojo es distinto del de Revilla, puesto que los hermanos Maeztu tuvieron ocasión de conocerlo y tratarlo personal e intelectualmente. Como hemos adelantado, Perojo murió en su escaño del Parlamento defendiendo las posiciones del Partido Liberal Canario a propósito del llamado "pleito canario». Como enseguida vamos a ver, el propio Ramiro fue el encargado de escribir la necrológica en el semanario Nuevo Mundo, fundado y dirigido por Perojo. Esto manifiesta una relación que se había vuelto muy intensa en los últimos años de vida de Perojo, pero que tenía orígenes familiares. Sabemos por testimonios del propio Ramiro que su padre, Manuel de Maeztu Rodríguez, tuvo un contacto estrecho con Perojo y que compartieron inquietudes comunes en el círculo anglófilo cubano al que ambos pertenecieron. No es casual que Perojo terminara coincidiendo, ahora con su hijo Ramiro, en sus primeros años en Inglaterra y que la familia Maeztu heredara Nuevo Mundo, continuando el proyecto editorial de Perojo diez años más allá de su fallecimiento. De hecho, Ramiro publicó un artículo en cada uno de los números de Nuevo Mundo desde el 3 de octubre de 1907 (todavía en vida de Perojo) hasta el 17 de mayo de 1918: cerca de quinientas colaboraciones en total. Algunos otros acontecimientos familiares vienen a abundar en la estrecha relación entre Perojo y los Maeztu, que superaba el ámbito meramente intelectual, por cuanto Miguel de Maeztu (hermano de Ramiro y María) se casó con Ana de la Cortina, compañera sentimental de Perojo desde su estancia en Filipinas hasta su muerte, y con quien tuvo dos hijos: el pionero de la aviación española José Perojo (que tiene el mismo nombre que su padre) y el ya citado Benito Perojo. Por este motivo, la familia Maeztu heredó el legado intelectual de José del Perojo y una continuidad de la que participaría Ortega con sus propios proyectos. En resumen, Perojo y los Maeztu no sólo compartieron concepciones acerca de la filosofía, la literatura, el periodismo, etc., sino también inquietudes y posiciones muy próximas durante la última etapa de aquél, que coincide con la juventud de Ramiro y María: 1) en el ámbito político, su pertenencia al círculo más íntimo de Antonio Maura, testificada incluso por Miguel de Unamuno, quien en una carta a Ortega fechada el 26 de marzo de 1908 citaba explícitamente a Perojo y a Ramiro de Maeztu en la lista de figuras más relevantes del maurismo y añadía «Me da miedo eso del maurismo de los Azorín, Perojo, Canals, Maeztu, etc., etc. Parece la gente trastornada.» ${ }^{7} ; 2$ ) en el ámbito ideológico, sus coincidencias en el diagnóstico sobre la

7 Robles Carcedo, L. (Edición y notas), Epistolario completo Ortega-Unamuno. Madrid, Ediciones El Arquero, 1987, carta XVII (26 de marzo de 1908), págs. 82-83. 
situación de España defendida por aquellos años por los regeneracionistas, en este caso, en sus posiciones más conservadoras; 3 ) en las propuestas de superación del atraso de España, necesitado de una intervención pedagógica de amplio calado que venía a coincidir, desde otros presupuestos doctrinales, con la de los institucionistas.

Así, en este círculo al que pertenecían Perojo y los Maeztu se configuraban los fundamentos del neoconservadurismo español, separado ya del viejo pensamiento reaccionario de comienzos del XIX y de las variantes que éste había tenido a lo largo del resto del siglo (carlistas, neocatólicos, «mestizos», etc.), establecido sobre bases ideológicas heredadas de las clases medias inglesas, con un carácter laico, defensor de valores próximos a la tradición protestante (trabajo, riqueza, dinero) y de carácter fuertemente europeísta.

En vista de estas relaciones que fuimos descubriendo, decidimos dedicar una primera fase de nuestro proyecto a conocer lo mejor posible la conexión de los Maeztu con los autores del primer movimiento neokantiano español (Perojo y Revilla). Si la figura filosófica que centra todo el debate es Kant, podemos hacer notar la gran coincidencia que existe entre la fecha en que Ramiro comenzó a hablar del filósofo alemán y la vuelta de Ortega de su primer viaje a Alemania: se trataba, pues, de buscar una tradición de referencia alternativa al viejo idealismo krausista y al escolasticismo para fundamentar la renovación filosófica y cultural de España. Aquí se encontraron Ramiro y Ortega: el Maeztu amigo de Perojo y lector de Revilla con el joven universitario Ortega. El primer artículo donde hemos comprobado que Ramiro habla de Ortega es «Gladstone y la obstrucción», publicado precisamente en Nuevo Mundo el 30 de abril de 1908, cuando Perojo aún estaba vivo y era su director. Por otra parte, resulta revelador que Maeztu confesara en su artículo "Grandmontagne en América» (Nuevo Mundo, 22 de octubre de 1908) que había comenzado a leer a Kant, justo cinco días después de haber fallecido su amigo Perojo y una semana antes de publicar su necrológica en Nuevo Mundo (significativamente titulada «Nuestro muerto», 29 de octubre de 1908).

Además, hay que señalar que Ramiro y su hermana María habían estado junto a Perojo en Inglaterra muy poco antes de su muerte. Efectivamente, el gobierno español envió a Perojo a Inglaterra en el verano de 1908 para que coordinara, junto a Alejandro San Martín y a Eduardo Sanz Escartín, los trabajos de una comisión de maestros españoles pensionados por el Ministerio de Instrucción Pública a propuesta de la Junta para Ampliación de Estudios e Investigaciones Científicas: entre estos pensionados se encontraba María de Maeztu. A esta comisión se le había asignado el cometido de estudiar las escuelas inglesas y la sección pedagógica de la Exposición franco-británica, coincidente con el Congreso Internacional de Educación Moral que se iba a celebrar en la Universidad de Londres del 25 al 29 de septiembre. De hecho, Perojo, junto a los citados San Martín y Sanz Escartín, fue nombrado Delegado oficial del Ministerio de Instrucción Pública para ese Congreso Internacional y, posteriormente, recibió el cargo de Secretario para los asuntos referentes a España formando parte del Comité General del Congreso. Por otra parte, fue el propio Perojo quien propuso y consiguió que Gumersindo de Azcárate y Eduardo Sanz Escartín ocuparan dos de las vicepresidencias de este evento ${ }^{8}$. Como resulta evidente, en ese tiempo Perojo era una figura de notable peso político y uno de sus ámbitos principales de actuación era el de la instrucción pública.

8 Para lo que se refiere a la intervención de Perojo en estos acontecimientos, pueden consultarse Anónimo: Presentación de los Anales de la Junta para Ampliación de Estudios e Investigaciones Científicas, Madrid, 1909, tomo I, págs. V-VI y SAnz Escartín, (Ed.), «La educación moral». Anales de la Junta para Ampliación de Estudios e Investigaciones Científicas. Madrid, 1909, tomo I, págs. 2-60. 
No voy a extenderme aquí sobre el pensamiento educativo de Perojo durante la última etapa de su vida ni el papel primordial que reservaba a la educación en sus proyectos de modernización de España. Basta con señalar que sus nuevas responsabilidades encajaban a la perfección con sus planteamientos pedagógicos de raigambre kantiana o neokantiana, que guardaban una estrecha relación con los de Ramiro y María de Maeztu y que incluían la formación permanente del profesorado con actividades de este calibre. Incluso es posible que la presencia de María en la comisión no fuera una casualidad ajena a la intervención de Perojo porque, como acabamos de mostrar, éste tenía poder suficiente para influir en las decisiones de la Junta para Ampliación de Estudios y del Ministerio de Instrucción Pública. En cuanto a Ramiro, coincidió también con él, pues fue el enviado especial del semanario Nuevo Mundo, probablemente a instancias de su director —el propio Perojo-, encargado de escribir la crónica de esta visita ( «La comisión de maestros», Nuevo Mundo, 17 de septiembre de 1908) y de presentar a su público el Congreso Internacional de Educación Moral («El Congreso de Educación moral», Nuevo Mundo, 24 de septiembre de 1908).

Sin embargo, no era la primera vez que Ramiro viajaba a Inglaterra en compañía de Perojo, porque en este mismo orden de cosas debe situarse su artículo «Lo de las escuelas» (Nuevo Mundo, 20 de febrero de 1908), en el que relataba su visita a la escuela de Peterborough en compañía de Perojo y hablaba (sin nombrarla) de su hermana María y de sus experiencias como directora de la Escuela Municipal de Párvulos de Bilbao. De hecho, a requerimiento de Ramiro, Perojo ofreció ese mismo día un artículo con las estadísticas sobre escuelas, maestros y alumnos en Inglaterra y su comparación con el estado de la educación en España («Sin título», Nuevo Mundo, 20 de febrero de 1908).

¿En qué posición quedaba María dentro de estas relaciones de Perojo y los Maeztu? En primer lugar, como acabamos de ver, su hermana y su pensamiento pedagógico estaban semiocultos en varios artículos de Ramiro, quien a veces la citaba, mientras que otras empleaba sus ideas y experiencias sin mencionarla explícitamente. Lo que concuerda con el papel que las mujeres de su tiempo desempeñaban en las actividades públicas o profesionales, en las que o no participaban o quedaban relegadas a un segundo plano dentro de muchos círculos intelectuales. Eso no quiere decir que María no manifestara su pensamiento pedagógico en otros ámbitos y por otros medios, pero sí que permanecía claramente marginada de la potente maquinaria de publicidad de Perojo, quien en cierta medida utilizaba a su hermano Ramiro como caja de resonancia de sus propios planteamientos pedagógicos.

También hay que señalar cómo muy significativamente Ortega fue nombrado al año siguiente (24 de julio de 1909) profesor numerario de Psicología, Lógica y Ética de la recién creada Escuela Superior del Magisterio, teniendo como alumna a la propia María de Maeztu, a quien sugirió que viajara a Alemania para conocer el pensamiento del segundo movimiento neokantiano alemán (Escuela de Marburgo). Aunque, como hemos comprobado, es muy posible que María ya conociera el primer movimiento neokantiano alemán (Escuela de Heidelberg) a través de Perojo y es totalmente seguro que había asumido ya planteamientos pedagógicos de raigambre kantiana y neokantiana.

Tenemos, pues, dos nexos: uno de carácter filosófico y otro de carácter pedagógico. Los principales estudiosos actuales de la figura de Ramiro han subrayado esta conexión entre Ortega y los Maeztu (sobre todo con Ramiro), pero prácticamente nada su conexión con los primeros neokantianos españoles, en este doble carácter filosófico y pedagógico. Nos queda pendiente concretar las diferencias que tendrían a partir de ese momento los herederos del discurso institucionista de raíz krausista y los herederos del discurso kantiano en su versión neokantiana, así como la influencia de esta última línea 
pedagógica en el pensamiento educativo de Ortega. Este es un objetivo futuro del grupo, que incluiría la publicación de los artículos pedagógicos y otros textos relacionados, tanto de Perojo como de los Maeztu. De esta manera, podrían precisarse las fuentes de influencia en el pensamiento educativo de Ortega y, no menos, fijar las trayectorias intelectuales y políticas de los herederos de ambas tradiciones.

\section{APUNTES SOBRE LA INFLUENCIA DEL PRIMER NEOKANTISMO ESPAÑOl SOBRE EL PENSAMIENTO pedagógico de María de Maeztu}

Para terminar, querría, a modo de ejemplo, referirme muy brevemente a la memoria de María sobre los centros educativos ingleses y la sección pedagógica de la Exposición franco-británica, titulada «La pedagogía en Londres y las escuelas de párvulos», publicada en 1909. Se trata de un texto en el que son patentes los rasgos que antes mencionamos: en el ámbito ideológico, coincidencias en el diagnóstico sobre la situación de España defendido por aquellos años por los regeneracionistas neoconservadores, establecido sobre las citadas bases ideológicas; en el educativo, propuestas de superación del atraso de España, necesitado de una intervención pedagógica de amplio calado que venía a coincidir, desde otros presupuestos doctrinales, con la de los institucionistas, aunque desde una orientación kantiana o neokantiana que, en 1909, es eminentemente fröebeliana. Esto es, en la que se conjugan la pedagogía krausiana con la pedagogía pestalozziana, esta última de raigambre rousseauniana-kantiana. Y en ambos aspectos, ideológico y educativo, María coincide plenamente con el tratamiento que Perojo hace de ellos en sus Ensayos sobre educación de 1907, anteriores, por tanto, en dos años al texto de María. ¿Significa esto que María se apoyó directamente en las ideas de Perojo? Esto es algo bastante más difícil de afirmar con fundamento que en el caso de su hermano Ramiro. Si atendemos a la primacía cronológica, Perojo habría sido la fuente de los hermanos Maeztu. Pero si nos centramos en la potencia del pensamiento pedagógico, María ostenta sin duda la supremacía. En definitiva, Ramiro, María y Perojo formaban parte de un mismo grupo y debatían sobre temas y problemáticas comunes, por lo que es realmente complicado para los historiadores del pensamiento alcanzar una conclusión definitiva al respecto. Lo que sí está claro es que los hermanos Maeztu no fueron meros discípulos de Ortega, sino también maestros suyos, pues éste participó en alguna medida de su influencia y de la de Perojo.

Recapitulando, he ofrecido algunas breves pinceladas de los puntos de contacto o influencias que existen entre José del Perojo y Manuel de la Revilla y los hermanos Ramiro y María de Maeztu, quienes a su vez representan el eslabón intermedio entre los primeros neokantianos españoles y José Ortega y Gasset, en su doble condición de maestros y discípulos de éste. Por eso puede decirse que Perojo y Revilla son en cierta medida precursores de Ortega, aunque no en el sentido de que el pensamiento de Ortega sea una copia o reproducción del suyo.

\section{BiBLIOGRAFÍA}

Anónimo, «Die Philosophie in Spanien». Philosophische Monatshefte, Leipzig, 1875, XI Band.

Anónimo, Presentación de los Anales de la Junta para Ampliación de Estudios e Investigaciones Científicas, Madrid, 1909, tomo I, págs. V-VI.

díaz Regadera, Ma . D. \& Hermida, F. \& Mora, J. L. \& Núñez, D. \& Ribas, P. (Estudio introductorio, edición y notas), Artículos filosóficos y políticos de José del Perojo (1875-1908). Ediciones de la Universidad Autónoma de Madrid, col. de Estudios, nº 86, 2003. 
Díaz Regadera, Mª . D., José del Perojo y Figueras (1850-1908). Neokantismo y reformismo. Ediciones de la Universidad Autónoma de Madrid, col. «Tesis en michoficha», 1996.

Dorca, T., Los albores de la crítica moderna en España: José del Perojo, Manuel de la Revilla y la «Revista Contemporánea». Valladolid, Universitas Castellae, Anejos Siglo Diecinueve, Monografías 3, 1998.

Fernández Urbina, J. M., La aventura intelectual de Ramiro de Maeztu, Vitoria, Diputación Foral de Álava, 1990.

Fructuoso Ruiz de Erenchun, Ma . C., María de Maeztu Whitney, una vitoriana ilustre. Vitoria, Real Sociedad Vascongada de los Amigos del País, 1998.

García BARRón, C., Vida, obra y pensamiento de Manuel de la Revilla. Madrid, José Porrúa Turanzas, 1987.

González Cuevas, P. C., Maeztu: biografía de un nacionalista español. Madrid, Narcial Pons Historia, 2003.

- La tradición bloqueda: tres ideas políticas en España: el primer Ramiro de Maeztu, Charles Maurras y Carl Schmitt. Madrid, Biblioteca Nueva, 2002.

Gubern, R., Benito Perojo. Pionerismo y supervivencia. Madrid, Filmoteca Española, Instituto de la Cinematografía y de las Artes Audiovisuales, 1994.

Hermida, F. \& Mora, J. L. \& NúÑez, D. \& Ribas, P. (Estudio introductorio, edición y notas), Manuel de la Revilla: Obras completas. Ediciones de la Universidad Autónoma de Madrid, 2006, tomos I, II y III.

Maeztu Whitney, $\mathrm{M}^{\mathrm{a}}$. de, «La pedagogía en Londres y las escuelas de párvulos». Anales de la Junta para Ampliación de Estudios e Investigaciones Científicas, Madrid, 1909, tomo I, págs. 288-315.

Maeztu Whitney, R. de, «Lo de las escuelas». Nuevo Mundo, Madrid, 20 de febrero de 1908.

— «Gladstone y la obstrucción». Nuevo Mundo, Madrid, 30 de abril de 1908.

— «La comisión de maestros». Nuevo Mundo, Madrid, 17 de septiembre de 1908.

— «El Congreso de Educación moral». Nuevo Mundo, Madrid, 24 de septiembre de 1908.

— «Grandmontagne en América». Nuevo Mundo, Madrid, 22 de octubre de 1908.

- «Nuestro muerto». Nuevo Mundo, Madrid, 29 de octubre de 1908.

- Don Quijote, Don Juan y La Celestina: ensayos en simpatía. Madrid, Calpe, 1926.

Menéndez Pelayo, M., «Mr. Masson, redivivo». Revista Europea, Madrid, 30 de julio de 1876.

— «Mr. Masson, redimuerto». Revista Europa, Madrid, 24 de septiembre de 1876.

Núñez, D., La mentalidad positiva en España: desarrollo y crisis. Madrid, Túcar, 1975.

Ortega y Gasset, J., Meditaciones del Quijote. Madrid, Imp. Clásica Española, 1914.

Palacios Fernández, E., Ramiro de Maeztu: la labor literaria de un periodista (1897-1910). Vitoria, Diputación Foral de Álava, 1982.

Pérez-Villanueva Tovar, I., María de Maeztu: una mujer en el reformismo educativo español. Madrid, Universidad Nacional de Educación a Distancia, 2003.

Perojo Figueras, J. del, «La Ciencia española bajo la Inquisición». Revista Contemporánea, Madrid, 15 de abril de 1877.

- Ensayos sobre educación. Madrid, Imprenta de Nuevo Mundo, 1907.

- La educación española. Madrid, Imprenta de Nuevo Mundo, 1908.

Robles Carcedo, L. (Edición y notas), Epistolario completo Ortega-Unamuno. Madrid, Ediciones El Arquero, 1987, carta XVI (19 de marzo de 1908), págs. 80-81 y carta XVII (26 de marzo de 1908), págs. 82-83.

SANTERVÁs Santamarta, R., La etapa inglesa de Ramiro de Maeztu. Madrid, Editorial de la Universidad Complutense, 1987.

SANZ Escartín, E., «La educación moral». Anales de la Junta para Ampliación de Estudios e Investigaciones Científicas. Madrid, 1909, tomo I, págs. 2-60.

Villacañas, J. L., Ramiro de Maeztu y el ideal de la burquesía en España. Madrid, Espasa Calpe, 2002.

Departamento de Antropología Social

Fernando Hermida de Blas

y Pensamiento Filosófico Español

Facultad de Filosofía y Letras

Universidad Autónoma de Madrid

fernando.hermida@uam.es

[Artículo aprobado para publicación en diciembre de 2012] 